\title{
काँगड़ा की लोकगाथाओं में स्त्री शोषण व प्रतिकार के स्वर
}

JANMAJAY SINGH GULERIA

Research Scholar, Depertment of Music, Panjab University Chandigah

\section{सार संक्षेपिका}

आज स्त्री को लेकर जो प्रश्न उठाए जाते हैं तथा जिनके समाधान के लिए विचार-विमर्श होता है। गोष्ठियां आयोजित होती हैं, मंच बनाए जाते हैं। वे सब प्रश्न इन लोकगाथाओं में है और इनके समाधान के संकेत भी हैं। काँगड़ा की कुछ प्रचलित लोकगाथाओं में पुरूष के अहम व अहंकार स्वरूप स्त्री के प्रति हुए अत्याचारों का वर्णन है। जिसमें प्रत्यक्षतः तो स्त्री के शोषण का चित्रण है लेकिन अप्रत्यक्ष रूप में स्त्री विरोध व प्रतिकार का स्वर भी है। पुरूष वर्चस्व का चित्रण इनमें है और नारी शोषण के मनोनीत हथकण्डे हैं। जिन हथकण्डों और षडयन्त्रों का शिकार होकर भी ये स्त्री पात्र बहुत कुछ कह गए हैं। अपने साथ हुए अनाचार व अन्याय के प्रतिकार के रास्ते बता गए हैं। ये नारी पात्र निशब्द क्रान्तियां हैं। अनाचार व अन्याय के विरूद्ध ऐसा विद्रोह है जो आने वाली पीढ़ियों को दिशा संकेत देने में समर्थ है।

बीज शब्द

काँगड़ा, लोकगाथा, स्त्री शोषण

भूमिका

लोक साहित्य के विविध रूप हैं। लोकगीत, लोकगाथाएं व लोक आख्यान। लोकगाथा को कथागीत की संज्ञा भी दी गई है। जिसमें गीत और कथा का मिश्रित आनन्द प्राप्त होता है। इन लोकगाथाओं के कथानक आवरण में करूणा, प्रेम, प्रतिस्पर्धा, ईर्ष्या, द्वेष, कलह आदि कितने ही ऐसे बिन्दू हैं जो स्वर, लय और गति के साथ मिलकर लोक जीवन की त्रासदियों का इतिहास निर्मित कर देते हैं।

संगीतात्मक नाटय प्रस्तुतियाँ लोकमानस का प्रिय क्षेत्र रहा है। जिसके अन्तर्गत भगत, स्वांग, ऐंचलियाँ आदि प्रसिद्ध हैं। बहुधा इन्हीं के साथ लोग-गाथाओं का नाटय रूपांकन भी किया जाता है। वास्तव में लोक गाथाएं मस्तिष्क नहीं परिस्थिति व घटना जन्य होती हैं। किसी स्थान विशेष से सम्बद्ध तथा वहां घटी किसी घटना या दुर्घटना का भावनात्मक क्रमबद्ध संगीतात्मक वर्णन लोकगाथा है। ये लोकगाथाएं उस स्थान या समाज विशेष की जीवन दृष्टि तथा वैचारिक आग्रह/दुराग्रह का चित्रण होता है। समाज सदैव इनके निरूपण तथा विश्लेषण से अपने लिए दृष्टि तथा रास्ता खेजने में प्रयासरत रहता है। ये ऐसे माणिक-मोती होते हैं जिनकी आभा हमारे अन्धेरे हृदय में उजाला कर देती हैं। हमारे सामने यथार्थ चित्रण करती हुई गाथाएं अन्ततः आर्दश स्थिति की ओर संकेत कर जाती हैं। किसी घटना/दुर्घटना की प्रतिक्रिया स्वरूप उल्लास व विषाद के अतिरेक में, किसी पद्धति या रीति के मानदण्डों से पूर्णतया अनभिज्ञ रहते अनायास ही जो बीज रूप में एक व्यक्ति द्वारा सृजित होती हैं। मौखिक रूप में ही परिमार्जित व परिवर्द्धित होते-होते एक पीढ़ी से दूसरी पीढ़ी तक पहुँचते, सर्जक से विलग कर समूह की हो जाती है। वे 
केवल लोक-गाथाएं ही नहीं संदर्भित अंचल या स्थान का ऐसा दर्पण हैं जिसमें लोकमानस अपना रूप-स्वरूप देखता और पहचानता है।

पुरूष प्रधान समाज में स्त्री पर पुरूष के निर्णय व आदर्श थोपे जाते हैं। कई बार ये बहुत अनीति पूर्ण तथा दमनकारी सिद्ध होते हैं। काँगड़ा की कुछ प्रचलित लोकगाथाओं में पुरूष के अहम व अहंकार स्वरूप स्त्री के प्रति हुए अत्याचारों का वर्णन है। जिसमें प्रत्यक्षतः तो स्त्री के शोषण का चित्रण है लेकिन अप्रत्यक्ष रूप में स्त्री विरोध व प्रतिकार का स्वर भी है। बहुत हैरानी होती है कि जिस स्त्री चिन्ता को आधुनिक समय में मनन व विश्लेषण के बाद समाधान की ओर ले जाने का प्रयत्न दम्भपूर्वक प्रचारित-प्रसारित किया जा रहा है। वह इन लोक-गाथाओं में वर्षों पहले सहज रूप में वर्णित है। एक-एक लोक गाथा यदि स्त्री के साथ हुए अन्याय की करूण कहानी है तो विद्रोह का झंडा उठाती नारी चेतना का दर्शन भी है। लेकिन यह दर्शन सतह पर नहीं है। कथा रूपी सागर की गहराई में छुपा मोती है जिसे गहरे में ही डूब कर पाया जा सकता है। लोकगाथाओं के मूल रूप, उनके भावार्थ तथा प्रतीकार्थ से यह स्वयं ही स्पष्ट हो जाएगा।

काँगड़ा की ये लोकगाथाएं गेय तथा संगीतात्मक हैं। ये गीतों के रूप में कलाकारों द्वारा गाई जाती हैं। परन्तु अति प्राचीन परपरा के अन्तर्गत चैत मास का नाम घर-घर जाकर बड़भागियों को सुनाने वाले लोकगायकों (जिन्हें ढोलरू वाले कहा जाता है) द्वारा इन्हें गाया जाना बहुत महत्वपूर्ण हैं। इन गाथाओं के केन्द्र में नारी है। और सभी में वह पीड़ित तथा श्रापित है।

काँगड़ा में एक प्रसिद्ध पर्यटक स्थान है धर्मशाला। इसके समीप चड़ी नाम का गाँव स्थित है। वहां की एक चर्चित लोक गाथा है - रूल्हा दी कुल्ह

सुते जे राणे हो राती, सुपना जे होया

रूल्हा दिया कुल्हा ओ बल लेई वो लैणी अद्धी-अद्धी राती ओ राणे हुक्म जे भेजेया रूल्हा दिया कुल्हा वो जातरा जाई वो रेईयां लिखेया परवाना हो सौह्रें नूओं जो भेजेया रूल्हा दिया कुल्हा वो जातरा जाई वो रेइयां दिये दिया लोई हो गोरिया कागद पड़ेया नैणा ते छम-छम रोई वो रहि ए

इस गाथा का सम्बन्ध वहां के संभात-सम्मानित राणा वंश से है। खेती ही उस समय जीवन यापन का साधन थी। एक बार वर्षा न होने से वहाँ अकाल पड़ गया। फ़सलें सूखने लगी क्योंकि सिंचाई का एकमात्र साधन कूल्ह भी सूख गई। चिन्ताग्रस्त वंश के मुखिया राणा जी को एक रात स्वप्न आता है। कूलह की देवी ने रात को राजा को दर्शन दिये व कहने लगी कि राजा तुमने कुल्ह की खुदवाई का काम पूरा करवा दिया है किन्तु अब तुम्हें बलि चढ़ानी पड़ेगी। वह एक-एक 
करके घर की वस्तुओं व सदस्यों के नाम लेती है। किसी न किसी कारण से हर चीज़ व व्यक्ति घर के लिए जरूरी है। झाडू की बलि इसलिए नहीं दी जा सकती क्योंकि घर की बरकत चली जायेगी। इसी प्रकार बिल्ली व तोते की बलि से भी सात पीढ़ियों तक विलार हत्या लग जायेगी। पुत्र तो वंश वृद्धि करेगा उसकी बलि कैसे दी जा सकती है। बहुत सोच-विचार के बाद मायके गई बहू को बुला लाने के लिए कहार भेज दिये जाते हैं।

माँ के घर बेठी उनकी उस बहू को सुबह से ही कुमंगल का अंदेशा हो रहा है। वह माँ के गले लगकर बहुत रोती है कि पता नहीं फिर लौटेगी या नहीं। उसके ससुराल पहुँचने पर सब त्यारी कर दी गई है उसे दीवार में चिना देने की। यहाँ इस गाथा में बहुत ही करूण वर्णन है। वह अपने चिने जाने पर मिन्नत-मनुहार करती है। कहती है कि उसके पाँव न चिने जाएँ अन्यथा वह मायके कैसे जायेगी। बांहे खुली रहने दी जाएं अन्यथा भाईयों से कैसे मिल पायेगी। वक्ष खुला रहने दिया जाए ताकि बेटा घुंघरु स्तनपान कर सके। नयनों से वह पिया को निहारना चाहती है। पर अन्ततः वह चिन दी जाती है। अपनी खुशहाली के लिए पराये घर की बेटी की बलि के नाम पर हत्या कर दी जाती है।

प्रेम लोक मानस का प्रिय विषय रहा है। संयोग के सुख का चित्रण बहुत हुआ है तो वियोग का चित्रण भी उतना ही मार्मिक है। एक प्रेम गाथा है गल्लां होई बीतियां :

गुआडुऐं पछाडुऐं तूं कजो झांकदी, झांकां कजो मारदी

दो हत्थ बुटणे दे लायां फुलमू, गल्ला होई बीतियां बूटणा लगान तेरियां सक्कियां भाभियां, तेरियां ताइयां-चाचियां

जिन्हां जो ब्याहे दा चॉ ओ रांझू, गल्ला होई बीतियां मैं तां होया मजबूर फुलमू, तिज्जो ते दूर फुलमू पंडतां कित्ता मेरा नास वो फुलमू, गल्लां होई बीतियां जिन्ही ताँ बाह्मणे तेरा ब्याह रखेया, ओ ब्याह सोध्या उसदी ना पाये परमेसर पूरी, गल्लां होई बीतियां बाह्मणां दा दोष नी किछ भी फुलमू, ऐह तां कर्मा दा लिखेया कर्मा दा लिखया नी मिटे फुलमू, गल्लां होई बीतियां जाणदी प्रीतां करी दुख भोगणा, जानी दुख भोगणा भुल्ली नी पांदी मैं प्रीत तेरी, गल्लां होई बीतियां इक्की पासे राँझू ब्याह्णा चलेया, ब्याह्णा चलेया दुये पासें फुलमू दी लाश चली, गल्लां होई बीतियां ठप्पा-ठप्पा कहारो मेरी पालकिया, मेरी पालकिया फुलमू जो दाग मैं देणा लोको, गल्लां होई बीतियां इक पासैं पफुलमू जो दाग दित्ता लोको दाग दित्ता 
दुए पासैं देई दित्ती छाल लोको गल्ला होई बीतियां

इस गीत का मूल संवेद्य है कि यदि मैं जानती, प्रेम करने से दुःख होगा तो कभी प्रीत न लगाती। प्रेम हर हृदय का सहज भाव है। परन्तु हर एक का प्रेम प्रतिफलित नहीं होता। बहुत बार दो प्रेमी एक नहीं हो पाते और विछोह उन्हें इतना व्याकुल कर देता है कि वे जी नहीं पाते। यह गीत भी दो प्रेम करने वालों की दुखान्त कहानी है। रचयिता इस कथा को कहते हुए इसे अतीत का प्रसंग कह रहा है। 'गल्ला होई बीतियां', वाक्य बार-बार दोहराया गया है अर्थात कही जा रही बातें हो चुकी है। प्रेमी जिसकी जबरन शादी की जा रही है वह (रांझू) अपनी प्रिया फुलमू को कहता है कि वह आगे-पीछे से झांक क्यों रही है। क्या देखना चाह रही है। आकर दो हाथ बुट्टणे (हल्दी-तेल व सुगन्धित द्रव्यों से तैयार सौन्दर्य प्रसाधन, विवाह अनुष्ठान का शुभारंभ) के क्यों नहीं लगती। नाराज प्रिया कहती है कि 'बुट्टणा', उसकी सगी भाभियां तथा ताई-चाचियां लगाएं, जिनके मन में चाव है। रांझू अपनी विवशता प्रकट करते हुए कहता है कि पंडित ने मेरा जीवन बर्बाद किया। फुलमू गुस्से से भरी लग्न सोधने वाले पंडित के लिए अपशब्द कहती है कि उसका कभी पूरा न पड़े। प्रेमी समझता है कि ब्राह्मण का कोई दोष नहीं। यह हमारे कर्मों में लिखा था। जिसे मिटाया नहीं जा सकता। वह कहती है कि यदि में जानती कि प्रेम करके दु:ख मिलता है तो कभी प्रेम न करती। एक तरफ रांझू विवाह करने को चलता है और दूसरी ओर फुलमू की लाश महायात्रा के लिए, ले जाई जाती है। संस्कार के स्थल पर रांझू कहारों से अपनी पालकी धरती पर रखवाता है कि उसने फुलमू को दाग (अग्नि) देना है। एक ओर उसे अग्नि देता है और दूसरी ओर छलांग लगा कर वह प्राण दे देता है।

स्वर लिपि

$\times$

\begin{tabular}{ccc|cccc|ccc|cccc}
- & - & - & - & - & सा & सा & ध & - & - & धसा & - & सा & सा \\
S & $S$ & $S$ & $S$ & $S$ & गु & $S$ & आ & $S$ & ड & ऐंड & $S$ & प & $S$ \\
रे & म & म & प & ध & ध & प & प & प & प & सा ध & प & म & ग \\
छा & $S$ & डु & ऐं & $S$ & तूं & $S$ & क & जो & $S$ & झां & $S$ & क & $S$ \\
रे & - & - & रे & ध & ध & प & प & प & - & स ध & प & म & ग \\
दी & $S$ & $S$ & झां & $S$ & कां & $S$ & क & जो & $S$ & मा & $S$ & र & $S$ \\
रे & - & - & रे & ग & रे & सा & साध & - & - & ध & सा & सा & - \\
दी & $S$ & $S$ & $S$ & $S$ & $S$ & $S$ & दोऽ & $S$ & $S$ & ह & $S$ & त्थ & $S$ \\
रे & म & म & प & ध & ध & प & प & - & - & ध & प & म & ग
\end{tabular}




\begin{tabular}{ccc|cccc|ccc|cccc}
\hline वु & ट & $S$ & णे & $S$ & दे & $S$ & ला & $S$ & $S$ & यां & $S$ & फु & ल \\
रे & - & - & रे & म & म- & - & प & थ & - & प & म & धप & म \\
मू & $S$ & $S$ & ग & $S$ & ल्लां & $S$ & हो & ई & $S$ & वी & $S$ & $S S$ & ति \\
म & रेग & पम & गरे & सा & सा & सा & - & - & - & - & - & - & - \\
यां & $S S$ & $S$ & $S$ & $S$ & $S$ & $S$ & $S$ & $S$ & $S$ & $S$ & $S$ & $S$ & $S$
\end{tabular}

प्रस्तुत गीत में स्थाई है। गीत की अन्य पंक्तियां भी इन्हीं स्वरों पर गाई जाएंगी।

एक अन्य लोकगाथा है जिसमें स्त्री अपने प्रेम को निर्दद्ध अभिव्यक्त करती है :

कुत्थूआं ते उगमी काली बादली, ओ मुंडुआ पिरथी सिंहा

कुत्थूआं ते उगमेया ठंडा नीर वे हां

छातिया ते उगमी काली बादली, ओ कुड़िये इंदरदेइए

नैणा ते उगमेया ठंडा नीर वे हां

कुन्हीं तां रंगी तेरी पगड़ी, ओ मुंडुआ पिरथी सिंहा

कुन्हीं तां कडेया रूमाल वे हां

भावो तां रंगीओ मेरी पगड़ी, ओ कुड़िये इंदरदेइए

नारा तां कडेया रूमाल वे हां

बिज तां कड़के तेरिया भाबियां, ओ मुंडुआ पिरथी सिंहा

नारा जो डस्से काला नाग वे हां

बिज तां हुंदी स्हाढ़ी कुलजज, नि कुड़िये इंदरदेइए

नाग तां कुले दा परोह्त वे हां

इस गाथा गीत में युवती इन्द्रदेई को युवक पृथी सिंह आकर्षित करता है। वह उससे जानना चाहती है कि वह विवाहित है या कुंवारा। बातचीत का सिलसिला आगे बढ़ता है और प्रेमी पुरूष द्वारा वह जान जाती है कि वह विवाहित है। यहाँ इस रचना में प्रेम में डूबी युवती प्राण नहीं देती ना ही किसी के प्राण लेती है। पर बड़ी महान व सुशील होने का नाटक भी नहीं करती। बल्कि प्रेमी को स्नेह देती उसकी भावज तथा उसकी पत्नी को अभिशाप देती है। यह एक ऐसी गाथा है जिसमें र्त्री ने अपने प्रेम की अभिव्यक्ति के बाद विफलता मिलने पर क्रोध किया है। स्वयं के अनिष्ट की बात नहीं सोची।

\section{उपसंहार}

इन सभी लोक गाथाओं के केन्द्र में स्थान विशेष में घटी घटनाएं रही होगी। परन्तु जागरूक चेतना तथा साहित्यिक व संगीतात्मक प्रतिभाओं ने इन घटनाओं को सुन्दर-मार्मिक व कलात्मक गीतों का रूप दिया है। आज रत्री को लेकर जो प्रश्न उठाए जाते हैं तथा जिनके समाधान के 
लिए विचार-विमर्श होता है। गोष्ठियां आयोजित होती हैं, मंच बनाए जाते हैं। वे सब प्रश्न इन लोकगाथाओं में है और इनके समाधान के संकेत भी हैं। पुरूष वर्चस्व का चित्रण इनमें है और नारी शोषण के मनोनीत हथकण्डे हैं। जिन हथकण्डों और षडयन्त्रों का शिकार होकर भी ये स्त्री पात्र बहुत कुछ कह गए हैं। अपने साथ हुए अनाचार व अन्याय के प्रतिकार के रास्ते बता गए हैं। ये नारी पात्र निशब्द क्रान्तियां हैं। अनाचार व अन्याय के विरूद्ध ऐसा विद्रोह है जो आने वाली पीढ़ियों को दिशा संकेत देने में समर्थ है।

सन्दर्भ

ढडवाल चन्द्रेखा (2009) काँगड़ा के लोक साहित्य में स्त्री विमर्श, हिमाचल मित्र, मुम्बई ढडवाल चन्द्रेखा (2012) काँगड़ा के लोक गाथाओं में नारी सरोकार अन्यथा प्रकाशन, लुधियाना दत्त जगदीश चन्द (1983) हिमाचली लोकगीत (भाग-1), भाषा एवं संस्कृति विभाग हि.प्र. शर्मा गौतम (1983) काँगड़ा इतिहास, संस्कृति एवं विकास, दिल्ली, जय श्री प्रकाशन 